\title{
The utility of the Historical Clinical Risk -20 Scale as a predictor of outcomes in decisions to transfer patients from high to lower levels of security-A UK perspective
}

\author{
Mairead Dolan ${ }^{1 *}$, Regine Blattner ${ }^{2}$
}

\begin{abstract}
Background: Structured Professional Judgment (SPJ) approaches to violence risk assessment are increasingly being adopted into clinical practice in international forensic settings. The aim of this study was to examine the predictive validity of the Historical Clinical Risk -20 (HCR-20) violence risk assessment scale for outcome following transfers from high to medium security in a United Kingdom setting.
\end{abstract}

Methods: The sample was predominately male and mentally ill and the majority of cases were detained under the criminal section of the Mental Health Act (1986). The HCR-20 was rated based on detailed case file information on 72 cases transferred from high to medium security. Outcomes were examined, independent of risk score, and cases were classed as "success or failure" based on established criteria.

Results: The mean length of follow up was 6 years. The total HCR-20 score was a robust predictor of failure at lower levels of security and return to high security. The Clinical and Risk management items contributed most to predictive accuracy.

Conclusions: Although the HCR-20 was designed as a violence risk prediction tool our findings suggest it has potential utility in decisions to transfer patients from high to lower levels of security.

\section{Background}

Over the last 3 decades there have been significant developments in the field of violence risk assessment and management. It is increasingly recognized that individuals with mental disorder have an increased (4 to 6 times higher) risk of committing a violent crime [1,2]. Since the work of Monahan [3] unstructured clinical approaches to risk assessment in psychiatric patients have been questioned due to their low levels of accuracy. The literature suggests that there are a number of factors that are associated with violence and poor outcome in patients discharged from civil and forensic settings including major mental illness, substance abuse and psychopathy [4-7]. Over the last 15 years there have

\footnotetext{
* Correspondence: mairead.dolan@forensicare.vic.gov.au

${ }^{1}$ Centre for Forensic Behavioural Science, Monash University and the Victorian Institute for Forensic Mental Health, 505 Hoddle Street, Clifton Hill, Victoria, 3068, Australia

Full list of author information is available at the end of the article
}

been notable developments in systematizing the risk assessment field which have led to the introduction of a number of risk assessment tools that provide a more structured approach to decision making $[6,8,9]$. The latter Structured Professional Judgment (SPJ) approach provides guidelines for assessing risk using systematized, empirically based, risk factors that can be coded but can still allow flexibility to take account of case-specific issues. One of the most researched instruments to use a SPJ approach is the Historical Clinical Risk-20 scale [8-10]. This measure has 10 historical, relatively static factors that do not change over time, and 10 dynamic (5 clinical and 5 risk management) items that are subject to change with treatment. See table 1 for item content. There are now a substantial number of international studies looking at the validity of the HCR-20 as a violence risk assessment tool. These include studies from Canada, Sweden, the Netherlands, Scotland, Germany, 
Table 1 HCR-20 item content

\begin{tabular}{cl}
\hline Historical Items \\
\hline$H 1$ & Previous Violence \\
\hline H2 & Young Age at First Violent Incident \\
\hline H3 & Relationship Instability \\
\hline H4 & Employment Problems \\
\hline H6 & Substance Use Problems \\
\hline H7 & Psychor Mental Illness \\
\hline H8 & Early maladjustment \\
\hline H9 & Personality Disorder \\
\hline H10 & Prior Supervision Failure \\
\hline & \\
\hline Clinical Items & \\
\hline C1 & Lack of Insight \\
\hline C2 & Negative Attitudes \\
\hline C3 & Active Symptoms of Major Mental IIness \\
\hline C4 & Impulsivity \\
\hline C5 & Unresponsive to Treatment \\
\hline
\end{tabular}

\begin{tabular}{cl}
\hline \multicolumn{2}{l}{ Risk Management Items } \\
\hline R1 & Plans Lack Feasibility \\
\hline R2 & Exposure to Destabilizers \\
\hline R3 & Lack of Personal Support \\
\hline R4 & Noncompliance with Redemption Attempts \\
\hline R5 & Stress \\
\hline
\end{tabular}

England and the United States. See [6,9-13]. Most of the published studies have focused on the validity of measures such as the HCR-20 in predicting in-patient and post discharge violence and aggression in male samples, although there is increasing data on female patients $[14,15]$.

Interestingly, we previously [16] looked at the predictive validity and clinical utility of the HCR-20 as a predictor of more generic post discharge outcome in patients discharged from medium secure care to the community in the UK. We found that the HCR-20 was a good predictor of self-reported violence, readmission, and particularly readmission under the criminal sections of the England and Wales Mental Health Act, 1986, but did not necessarily relate to the intensity of supervision post discharge. This suggested that the HCR-20 may be a useful instrument for assessing the risk of poor outcome (in more general terms than violent recidivism) in decisions to transfer patients from higher to lower levels of security including the community. This led us to wonder if this instrument had value in predicting outcome decisions across levels of security in the forensic rehabilitation process.
In England and Wales (E\&W) and most European and Canadian and United States (US) forensic services, the rehabilitation of high security patients who are detained in High Security Psychiatric Hospitals (HSPHs) usually occurs via transfer to progressively lower levels of security prior to discharge into the community $[17,18]$. Apart from the UK few jurisdictions have systematically looked at the outcomes of patients across levels of security and international comparative data is currently quite limited. A review of the medium to long term outcomes of discharges from HSPHs in E\&W, with follow up between 2-11 years, suggests that hospital readmission rates range between 7 - 22\% [19]. Reconviction studies of released HSPH patients also suggest that the rate of serious reconvictions ranges from $3 \%$ to $24 \%$ overall, [20-22]. However, Davison et al. [23] reported that rates were notably higher in patients with a diagnosis of Axis II personality disorder rather than an Axis I disorder.

A range of independent clinical studies suggest that poor outcome for HSPH patients appears to be linked with a variety of risk factors including; younger age, a higher number of previous convictions, a history of psychiatric admissions, mental impairment, psychopathy or a sexual index offence [19,24-26], but few of these risk factors have been examined together in the context of a comprehensive risk assessment protocol. Given that SPJ approaches to risk assessment have been adopted as good clinical practice in most US and European jurisdictions, but there is limited evidence on the applicability in clinical practice, we wanted to investigate the utility of the HCR-20 in decision making on transfers from high to medium and lower levels of security in a UK context.

Available data from the limited number of studies examining the outcomes of HSPH patients transferred to medium security in E\&W suggest that between 26$33 \%$ are returned to high security, and between $9-11 \%$ are reconvicted for serious offences [26-28]. Given the growing interest in the use of more structured clinical risk assessment and management tools in clinical decision making $[6,9,29-35]$, we investigated the potential utility of a Structured Professional Judgment (SPJ) approach to violence risk assessment using the Historical Clinical Risk violence risk scheme (HCR-20; [8]) in the decision to transfer cases between high and lower levels of forensic secure care. The HCR-20 has repeatedly been shown to be a robust predictor of institutional and community violence in mentally disordered samples across a range of settings and international centers [9,16,33-39].

We have previously shown that the HCR-20 was actually a useful predictor of self-reported violence and readmission to hospital in patients transferred from medium and low secure care to the community [16] and that 
clinically based supervision levels post discharge was unrelated to systematic risk assessment status [16]. As there was one report that suggested that the HCR-20 was useful in characterizing risk status in patients managed by community mentally health services in the UK [40], we examined its utility as an assessment tool in decisions to transfer patients from high to lower levels of security.

\section{Methods}

\section{Study participants}

The study was conducted in the Edenfield Centre Medium secure unit in the North West region of E\&W. The 2005-6 cohort under study was based on all HSPH patients admitted to the Edenfield medium secure unit (MSU) psychiatric facility from its inception in September 1986 to June 2001, and who had a terminated MSU admission episode by May 2002. That is, they had been discharged to the community or returned to the HSPH from the MSU by May 2002. In cases where a patient had several admissions to the MSU, the first admission was used as the index admission case for the purposes of this study. The study criteria generated a total of 72 consecutive patients discharged from HSPH to the Edenfield Centre whose index admission to the latter unit had terminated either through discharge to the community or lower levels of security (success), or transfer back to high security/reconviction (failure). Of all admissions to the Edenfield centre, this HSPH sample represented $11 \%$ of all admissions to the unit during that time period. The remainder of the transfers/admissions had come from prisons or from area/local mental health services. The majority were detained under section 41 (restriction order) of the UK Mental Health Act 1986. That is, the patients were detained in hospital following a court appearance for an offence that was deemed associated with mental disorder requiring inpatient treatment and whose discharge could only be approved by the Home Office (now Ministry of Justice) or following appeal to a Mental Health Review Tribunal.

The mean age of the HSPH cohort under study was 36.4 years $(\mathrm{SD}=11.5)$. Sixty- three $(87 \%)$ were male and 57 (79\%) were Caucasians. The remainder were of AfroCaribbean (10\%) or Asian/mixed race origin (11\%). Clinical case files, which record multi-axial diagnoses, indicated that the majority had an Axis I clinical diagnosis particularly schizophrenia, but there were high rates of co-morbidity with Axis II pathology. A significant proportion of the cohort met criteria for substance abuse dependence. Forty-seven patients (65\%) had more than one clinical diagnosis recorded. See table 2.

The majority $(55,76 \%)$ had previous admissions to a psychiatric hospital. Fifty-nine (82\%) had previous convictions with a range of 1-35 offences. The mean age at
Table 2 Clinical diagnosis according to DSM-IV (several diagnoses possible, $\mathbf{n}=\mathbf{7 2}$ )

\begin{tabular}{lc}
\hline Organic brain syndromes & $6(8 \%)$ \\
Schizophrenia or -related disorders & $48(67 \%)$ \\
Affective disorders & $4(6 \%)$ \\
Alcohol-related disorders (misuse or dependency) & $22(31 \%)$ \\
Substance-related disorders (misuse or dependency) & $22(31 \%)$ \\
Personality disorder & $22(31 \%)$ \\
Neurotic disorders & $3(4 \%)$ \\
Mental Impairment & $6(8 \%)$ \\
Co morbidity between disorders & $47(65 \%)$ \\
\hline
\end{tabular}

first conviction was 19.5 years $(\mathrm{SD}=8.3)$. The frequency of particular index offences were as follows; violence against others (64\%); violent sex offences (17\%); arson with intent to endanger life and criminal damage (19\%). See table 3.

Prior to transfer to the MSU, the mean length of stay at the $\mathrm{HSPH}$ was 7.4 years $(\mathrm{SD}=5.8)$. The majority (59, $82 \%$ ) were transferred to the MSU on trial leave to test their suitability for rehabilitation into the community. The mean length of MSU stay was 1.2 years $(\mathrm{SD}=1.0)$.

\section{Procedure}

The Local Research and Ethics Committee (LREC) granted approval for the study. Responsible Medical Officers (RMOs) gave consent for access to patient's files.

The HCR-20 was rated from the detailed case files based by a trained psychiatrist on the data available in the medium secure unit following transfer from high security. The case files were reviewed and the HCR-20 scored based on data available prior to their transfer out of, or discharge from, the medium secure unit, but this

\begin{tabular}{|c|c|}
\hline \multicolumn{2}{|l|}{ Offences against person } \\
\hline murder/manslaughter & $23(32 \%)$ \\
\hline attempted murder/serious wounding & $23(32 \%)$ \\
\hline \multicolumn{2}{|l|}{ Sexual offences } \\
\hline Rape & 7 (9.7\%) \\
\hline against children/teenagers & $3(4.1 \%)$ \\
\hline Other sexual offence & $3(4.1 \%)$ \\
\hline \multicolumn{2}{|l|}{ Offences against property } \\
\hline Arson & $14(19.4 \%)$ \\
\hline robbery/burglary & $10(13.8 \%)$ \\
\hline Other offences & $9(12.5 \%)$ \\
\hline No offence & $0(0 \%)$ \\
\hline Several offences $\mathrm{n}(\%)$ & $19(26.3 \%)$ \\
\hline
\end{tabular}

Other offences include: criminal damage, breach of peace, severely disorderly behaviour, kidnapping, possessing weapons or imitation firearms with intent, driving without licence and taking conveyance. 
was conducted blind to subsequent outcomes. The HCR-20 scale has ten Historical-H items, five Clinical-C items, and five Risk- $\mathrm{R}$ items. The $\mathrm{H}$ items are based on empirical literature on violence risk assessment and tend to remain static over time. The $\mathrm{C}$ and $\mathrm{R}$ items are amenable to change with intervention and supervision. All 20 items are coded using a " 0 " rating for absence of an item, " 1 " for possible presence of the item and " 2 " for definite evidence for this item. Descriptors and criteria for each item are provided in the manual [8] but HCR-20 items are listed in table 1.

\section{Outcome data}

Outcome was classed as "success" or "failure" based on the work of Quinn and Ward [27] and Cope and Ward [28] who used similar criteria for outcome measures in their study. Success was based on successful rehabilitation from the MSU to the community with no adverse events (readmission/reconviction) during the study period.

Failure was based on:

(i) Direct return to the HSPH,

(ii) Return to the HSPH after discharge to the community and

(iii) Reconviction for a serious offence after discharge to the community. Re-conviction data was extracted from combined sources including case files and the official records in the Offenders Index of the Home Office. A reconviction was regarded as being "serious" in cases of murder, manslaughter, assault, rape, indecent assault towards adult male, adult female or child, robbery and arson, based on the criteria of Bailey and MacCulloch [22].

\section{Data analysis}

Data were analyzed using the Statistical Package for Social Sciences SPSS for Windows (version 14) Chicago Illinois Inc. Where possible, outcome data was coded into dichotomous groups e.g. outcome present or absent. Receiver Operating Characteristics (ROC) analyses [28], were used to examine the predictive validity of the HCR-20 score for dichotomous outcome measures as they are relatively independent of the base rate for violence in a given population. ROCs also offer the advantage of plotting the trade-off between sensitivity (true positive rate) and 1-specificity (false positive rate). The Area under the curve (AUC) statistic ranges from 0 (perfect negative prediction) to 1 (perfect positive prediction) with 0.50 representing a chance level of prediction. ROC AUC statistics of 0.76 approximate to Cohen's $d$ of 1 which is considered a large effect size $[7,38]$.

\section{Results}

\section{General outcome}

Overall, 32 patients (44.4\%) were rated as having a successful outcome in that they were successfully rehabilitated to the community with no adverse events during the study period.

Forty patients (55.5\%) had an outcome that was classed as a "failure" based on the assigned categories. Thirty-three (46\%) patients returned directly to the high-security hospital from the MSU; one patient was recalled to the HSPH with treatment-resistant mental illness; one patient was recalled after a serious re-conviction and five further patients were re-convicted of serious offences.

\section{Reconviction data- Community outcomes}

Of the 39 patients (54\%) who were discharged to the community (mean 6 years SD 3.6), 8 (21\%) were reconvicted. Mean length of time until re-offending was 5.25 years $(\mathrm{SD}=3.7)$. Six $(15 \%)$ were for serious offences (violence against the person).

\section{The predictive validity of the HCR-20 for outcomes}

The mean total HCR-20 score was 22.06 (SD 7.2), The $\mathrm{H}$ score was 12.47 (SD 3.5), C was 4.29 (SD 3.0) and R 5.29 (SD2.5). Table 3 shows the ROC curve analyses for the total and subscale scores of the HCR-20 for "failed outcome". The HCR-20 total score was a reasonably robust predictor of "failure". Analysis of the subscale scores indicated that the $\mathrm{C}$ and $\mathrm{R}$ subscales rather than the $\mathrm{H}$ subscale were significantly better than chance predictors. See Table 4 and figure 1.

\section{Discussion}

To date, there are a limited number of studies looking at the forensic outcomes of high security patients who have been discharged via medium secure care $[27,28]$. In this study the $72 \mathrm{HSPH}$ patients had similar characteristics to those described in other MSUs e.g. [28,41-44] in that they were predominately male with extensive forensic and psychiatric histories. In a pseudo-prospective study design we examined the predictive accuracy of the HCR-20 for outcomes following transfer from high to

Table 4 HCR-20 subscale and total HCR-20 score as predictor for outcome "failure"

\begin{tabular}{lccccc}
\hline $\begin{array}{l}\text { HCR-20 } \\
\text { subscales }\end{array}$ & $\begin{array}{c}\text { Area under the } \\
\text { curve (AUC) }\end{array}$ & $\begin{array}{c}\text { Std } \\
\text { error }\end{array}$ & Significance & $\begin{array}{c}\mathbf{9 5 \%} \mathbf{C l} \\
\text { Lower }\end{array}$ & $\begin{array}{c}\mathbf{9 5 \%} \mathrm{Cl} \\
\text { Upper }\end{array}$ \\
\hline Historical & 0.59 & 0.069 & 0.16 & 0.46 & 0.71 \\
Clinical & 0.907 & 0.035 & 0.00 & 0.839 & 0.974 \\
Risk & 0.855 & 0.045 & 0.00 & 0.766 & 0.944 \\
Total & 0.863 & 0.041 & 0.00 & 0.783 & 0.943 \\
score & & & & & \\
\hline
\end{tabular}

$\mathrm{Std}=$ standard, $\mathrm{Cl}=$ confidence interval 


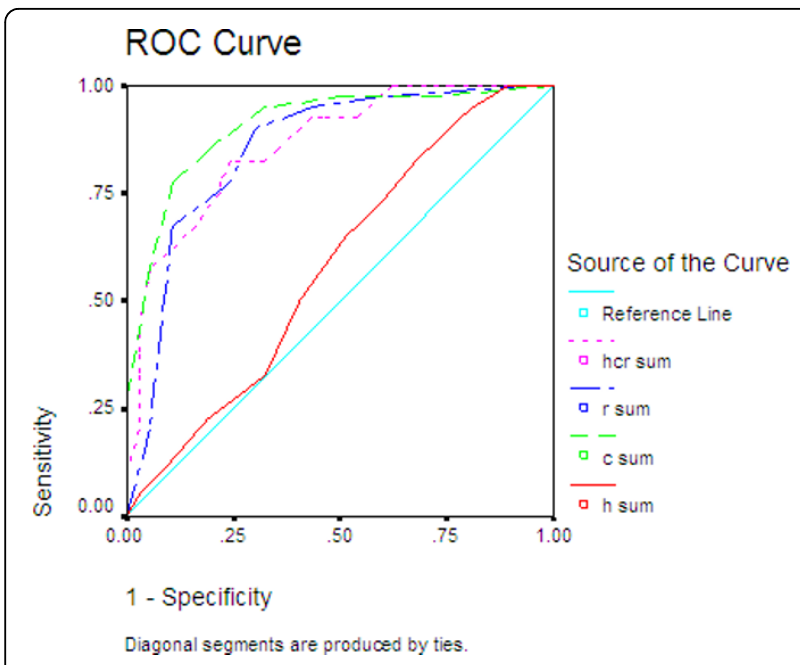

Figure 1 Area under curve: Historical, clinical and risk subscale as well as total HCR-20 score as a predictor of the outcome "failure".

medium secure psychiatric care. As far as we know this is the first international study to look at the HCR-20 in this way as most studies have focused on either institutional or community violence [12,16,29,33,35-37,45-48]. It is also the first to report data on the validity of this measure at predicting a broader range of outcomes following transfer to lower levels of security in the UK or elsewhere. We predicted that high scores on the Historical Clinical Risk -20 scale would be predictive of poor outcome in medium secure services. We did indeed find that the HCR-20 score was a good predictor of failed transfer. The total score ROC AUC curve was 0.86 which is much higher than the modest to moderate ROCs reported in many previous studies [9]. It is also noteworthy that it was the clinical and risk management subscales that contributed most to this effect. Studies have reported varying degrees of contribution from the dynamic subscales but the research evidence seems to suggest that the contribution of dynamic scales vary as a function of the stage of rehabilitation. In Gray's et al's [33] pseudo prospective 2 year follow up study of patients discharged from medium security to the community only the Historical and Risk scales were predictive. The clinical scales did not show notable accuracy. They suggest that the lack of predictive accuracy in their sample may reflect the clinical stability of those deemed suitable for discharge to the community as well as the differences in follow up time. Our finding that the clinical and risk items both contribute significantly to the prediction of poor outcomes fits with our previous studies in medium secure samples $[16,45]$ and also fits with the notion that the clinical items may be more robust predictors of negative outcomes if failure is also determined by clinical issues such as lack of response to medication. There are a number of studies that have compared the post discharge outcomes of patients and using the HCR-20 with Violence Risk Appraisal Guide [49] and the Psychopathy Checklist Revised [50] or Psychopathy Checklist- Screening Version (PCL;SV.[51]) which are measures of psychopathy that have been shown to be predictive of post discharge violence [52]. In one study [53] 193 psychiatric patients were assessed using both the HCR-20 and The PCL: SV. At 2 year follow up, the AUCs for the HCR-20 ranged from 0.760.80 for a range of aggressive and threatening behaviors, but the PCL: SV had only moderate predictive power. Interestingly, the HCR-20 had incremental validity over and above the PCL: SV. Similar findings were noted in our previous prospective 24 week follow up study of patients discharged from medium secures and civil psychiatric settings work who had been assessed using the HCR-20, VRAG and PCL:SV[45]. Here we found that the HCR-20 and PCL:SV were better predictors of violence post discharge than the VRAG, but in the regression analyses the HCR-20 (particularly the clinical and risk scales) had incremental validity over and above the PCL:SV [45]. A Swedish retrospective study on 40 male forensic patients [37] also found that the HCR-20 was highly predictive of violent recidivism and that the clinical and risk management scales predicted recidivism much better than the historical scale. Overall, our findings seem to suggest that the HCR-20 is a useful tool in predicting those who will fail in their rehabilitation. The broader literature also suggests that it has utility in predicting post discharge recidivism (particularly violent outcomes) for both forensic and correctional samples [9]. There is a growing literature that suggests it has utility in predicting in-patient aggression and outcome [35] although the findings have been less robust as in-patient aggression may be more associated with heightened affect and active psychotic symptoms in US studies [12]. While there is now little doubt that structured risk assessment instruments outperform clinical judgment for the prediction of violent behavior and poor outcome for predominately male samples $[6,11]$, there is relatively little data on female forensic or correctional samples. The vast majority of risk assessment studies in women have been based on psychopathy assessments $[54,55]$ and there is limited data on the validity and utility of the HCR-20 in women [56]. Some studies looking at gender differences in the HCR-20 do not note significant differences between men and women $[8,14]$ however, work by de Vogel \& de Ruiter [57] showed that the HCR-20 total score demonstrated lower predictive accuracy for violent outcome in women compared to men. Given the observed gender differences future studies need to address this issue[15]. 


\section{Limitations}

There are a number of limitations to this study including small sample size and a focus on a mainly male Caucasian cohort. Given recent reports that there are gender and ethnic differences in scores on some HCR-20 items this is an area that warrants further study $[14,15,64]$. Furthermore, although our cohort were fairly representative of patients detained in medium levels of security in the UK, they may not be comparable to cohorts of medium secure patients in other European and US jurisdictions where there may be greater representation of ethnic minority groups and female patients. It is also possible that the findings may not be generalisable to high security samples as this cohort had already been clinically selected as suitable for transfer to lower levels of security. In this study, we relied on clinical recording of multiaxial diagnoses, rather than standardized assessment tools. While the clinical files do record multi-axial diagnoses, it is possible that the lack of assessment using structured assessment tools may have resulted in under recording of Axis II and III pathology in particular.

\section{Conclusions}

The findings from this study would suggest that measures such as the HCR-20 may have value in routine clinical decisions as they may assist in the assessment of those who are likely to succeed or fail on trial leaves to lower levels of security. Although the HCR-20 is increasingly being adopted into clinical practice in European forensic settings including Germany, Sweden and the Netherlands, there are relatively few UK centers outside high secure forensic facilities that use the HCR-20 as a core component of routine clinical practice. The Edenfield Centre Medium secure unit in the North of England has adopted this instrument into routine clinical practice following a series of research based validation studies to examine its utility as part of its ongoing risk assessment research program. We have shown that it is a robust predictor of post discharge outcome (readmission and self report violence) in patients discharged from our medium secure service [16]. We have also shown that the HCR-20 is one of the most robust predictors of community violence 24 weeks post discharge in patients discharged from both forensic and civil psychiatric services [45]. More recent studies by Gray and colleagues [33] confirm the validity of the HCR-20 in the prediction of violent recidivism in patients discharged from medium secure units in the UK. Several services in the United States and Europe have also published research studies supporting its reliability, validity and clinical utility across a range of levels of security as well as the community [9]. A key strength of the HCR20 is its utility in guiding clinical judgment about risk management and it is this aspect of the instrument that has lead to its acceptance into routine clinical practice [13]. The development of the HCR-20 companion guide [10] has assisted with this process, but more work is needed to refine the role of structured risk assessment tools in clinical decision making [58]. Many studies rely on official records of reconviction as an outcome measure. We suggest that there are limitations in the use of reconviction data as a proxy measure of success in assessing the efficacy of forensic services $[59,60]$ including the fact that there may be bias in the prosecution of psychiatric patients which limits the accuracy of this data in assessing and comparing outcomes $[61,62]$. This however remains one of the most cited performance indicators. In recent years, there has been a move away from reliance on criminal outcomes alone and recent work suggests alternative measures such as readmission and collateral and self reported criminality may be useful indicators of outcomes [16,45]. Further studies are needed to track and monitor the mental health and criminal outcomes of patients discharged from high and lower levels of security and to compare the outcomes of patients who are discharged to the community and followed up using an integrated, as opposed to a parallel, model of aftercare [62].

\section{Acknowledgements}

$\mathrm{MD}$ and RB were funded by Greater Manchester West NHS Foundation Trust for the duration of the study. The study received no further external funding.

\section{Author details}

${ }^{1}$ Centre for Forensic Behavioural Science, Monash University and the Victorian Institute for Forensic Mental Health, 505 Hoddle Street, Clifton Hill, Victoria, 3068, Australia. ${ }^{2}$ Department of Psychiatry, Laureate House, Wythenshawe Hospital, Southmoor Road, Manchester M23 9LT.

\section{Authors' contributions}

MD conceived of the study, and participated in its design and coordination and drafted the manuscript. RB carried out the field work, assisted in data analysis and assisted in drafting the manuscript. All authors read and approved the final manuscript.

\section{Competing interests}

The authors declare that they have no competing interests.

Received: 16 March 2010 Accepted: 29 September 2010

Published: 29 September 2010

\section{References}

1. Hodgins S, Mednick SA, Brennan PA, Schulsinger F, Engberg M: Mental Disorder and crime. Arch General Psychiatry 1996, 53:489-96.

2. Swanson JW, Holzer CE, Ganju VK, Jono RT: Violence and psychiatric disorder in the community: evidence from the epidemiological Catchment Area survey. Hospital and Community Psychiatry 1990, 41:761-70.

3. Monahan J: Predicting violent behaviour: an assessment of clinical techniques Beverley Hills: (CA) Sage 1981

4. Monahan J, Steadman H, Silver E, Appelbaum P, Robbins P, Mulvey E, Roth L, Grisso T, Banks S: Rethinking risk assessment: The MacArthur Study of mental disorder and violence Oxford University Press 2001. 
5. Rice ME: Violent offender research and implications for the criminal justice system. Am Psychol 1997, 52:414-423.

6. Dolan MC, Doyle M: Violence risk prediction. Clinical and actuarial measures and the role of the Psychopathy Checklist. Br J Psychiatry 2000, 177:303-11.

7. Ogloff J, Lemphers A, Dwyer C: Dual diagnosis in an Australian forensic psychiatric hospital: Prevalence and implications for services. Behav Sci Law 2004, 22:543-562.

8. Webster CD, Douglas KS, Eaves D, Hart S: HCR-20: Assessing Risk for Violence, Version 2. Vancouver, Canada: Simon Fraser University 1997

9. Douglas K, Guy L: HCR-20 violence risk assessment scheme: overview and annotated bibliography 2006 [http://www.sfu.ca/psych/faculty/hart/resources. $\mathrm{htm}]$.

10. Douglas K, Webster C, Hart S, Eaves D, Ogloff J: HCR-20 Violence risk management companion guide Mental Health Law \& Policy Institute, Simon Fraser University and BC Forensic Psychiatric Services Commission 2002.

11. Ogloff J, Davies M: Assessing risk for violence in an Australian context. In Issues in Australian Crime and Criminal Justice Edited by: Chappell D, Wilson P 2005, 301-338

12. McDermott BE, Edens JF, Quanbeck CD, Busse D, Scott CL: Examining the role of static and dynamic risk factors in the prediction of inpatient violence: variable- and person-focused analyses. Law Hum Behav 2008, 32:325-38.

13. Belfrage $\mathrm{H}$ : Implementing the HCR-20 scheme for risk assessment. J Forens Psychiatry 1998, 9:328-338.

14. Strand S, Belfrage $\mathrm{H}$ : Comparison of HCR-20 scores in violent mentally disordered men and women: gender differences and similarities. Psychology Crime and Law 2001, 7:71-79.

15. Coid J, Yang M, Ullrich S, Zhang T, Sizmur S, Roberts C, Farrington DP Rogers RD: Gender differences in structured risk assessment: comparing the accuracy of five instruments. J Consult Clin Psychol 2009, 77(2):337-48.

16. Dolan MC, Khawaja A: The HCR-20 and post-discharge outcome in male patients discharged from medium security in the UK. Aggress Behav 2004, 30:469-83

17. Butwell M, Jamieson E, Leese M, Taylor PJ: Trends in special (high security) hospitals. Br J Psychiatry 2000, 176:260-5.

18. Snowden P: Regional secure units and forensic services in England and Wales. In Principles and practice of forensic psychiatry. Edited by: Bluglass R, Bowden P. Edinburgh: Churchill Livingstone; 1990:1375-86.

19. Bowden P: What happens to patients released from the Special hospitals? Br J Psychiatry 1981, 138:340-5.

20. Dell S: Transfer of special hospital patients to the NHS. Br J Psychiatry 1980, 136:222-34

21. Black DA, Spinks P: A 5-year follow-up study of male patients discharged from Broadmoor hospital: Characteristics of success and failure. Paper presented at the Annual Conference of the British Psychological Society, Exeter 1977.

22. Bailey J, MacCulloch M: Characteristics of 112 cases discharged to the community team from a new special hospital and some comparison of performance. J Forens Psychiatry Psychol 1992, 3:91-112.

23. Davison S, Jamieson E, Taylor PJ: Route of discharge for special (high security) hospital patients with personality disorder. Br J Psychiatry 1999, 175:224-7.

24. Buchanan A: Criminal conviction after discharge from special (high security) hospital. Br J Psychiatry 1998, 172:472-6.

25. Jones C, MacCulloch M, Bailey J, Shahtahmasebi S: Personal history factors associated with reconviction in personality disordered patients discharged from a special hospital. J Forens Psychiatry Psychol 1994, 5:250-61.

26. Blattner $\mathrm{R}$, Dolan $\mathrm{M}$ : Outcome of high security patients admitted to a medium secure unit - The Edenfield Centre study. Med Sci Law 2010, 49(4):247-56.

27. Quinn $P$, Ward M: What happens to special hospital patients admitted to medium security? Med Sci Law 2000, 40:345-9.

28. Cope R, Ward M: What happens to special hospital patients admitted to medium security? J Forens Psychiatry Psychol 1993, 4:14-24.

29. Douglas KS, Cox DN, Webster CD: Violence risk assessment: Science and practice. Legal and Criminological Psychology 1999, 4:149-184.

30. Otto RK: Assessing and managing violence risk in outpatient settings. $J$ Clin Psychol 2000, 56(10):1239-62.
31. Douglas KS, Kropp PR: A prevention-based paradigm for violence risk assessment: Clinical and research applications. Crim Justice Behav 2002, 29:617-658.

32. Dvoskin JA, Heilbrun K: Risk assessment and release decision-making: Toward resolving the great debate. J Am Acad Psychiatry Law 2001, 29:6-10.

33. Gray NS, Taylor J, Snowden RJ: Predicting violent reconvictions using the HCR-20. Br J Psychiatry 2008, 192:384-387.

34. Dernevik M, Grann M, Johansson S: Violent behaviour in forensic psychiatric patients: risk assessment and different riskmanagement levels using the HCR-20. Psychology Crime and Law 2002, 8:93-111.

35. Doyle M, Dolan M, McGovern J: The validity of North American risk assessment tools in predicting in-patient violent behaviour in England. Legal and Criminological Psychology 2002, 7:141-154.

36. Douglas KS, Webster CD: The HCR-20 violence risk assessment scheme: concurrent validity in a sample of incarcerated offenders. Crim Justice Behav 1999, 26:3-19.

37. Grann $M$, Belfrage $H$, Tengström A: Actuarial assessment of risk for violence: Predictive validity of the VRAG and the historical part of the HCR-20. Crim Justice Behav 2000, 27:97-114.

38. Mossman D: Assessing predictions of violence: Being accurate about accuracy. J Consult Clin Psychol 1994, 62:789-792.

39. Witt PH: A practitioner's view of risk assessment: The HCR-20 and SVR20. Behavioral Science and the Law 2000, 18:791-798.

40. Dowsett J: Measurement of risk by a community forensic mental health team. Psychiatr Bull 2005, 29:9-12

41. Coid J, Kahtan N, Gault S, Cook A, Jarman B: Medium secure forensic psychiatry services. Br J Psychiatry 2001, 178:55-61.

42. Ricketts D, Carnell H, Davies S: First admissions to a regional secure unit over a 16-year period: changes in demographic and service characteristics. J Forens Psychiatry Psychol 2001, 12:78-89.

43. Maden A, Rutter S, McClintock T, Friendship C, Gunn J: Outcome of admission to a medium secure psychiatric unit. 1. Short- and long-term outcome. Br J Psychiatry 1999, 175:313-6.

44. Edwards J, Steed P, Murray K: Clinical and forensic outcome 2 years and 5 years after admission to a medium secure unit. J Forens Psychiatry Psychol 2002, 13:68-87.

45. Doyle M, Dolan M: Predicting community violence from patients discharged from mental health services. Br J Psychiatry 2006, 189:520-6

46. Gray NS, Hill C, McGleish A, Timmons D, MacCulloch MJ, Snowden RJ: Prediction of violence and self-harm in mentally disordered offenders: a prospective study of the efficacy of the HCR-20, PCL-R, and psychiatric symptomatology. J Consult Clin Psychol 2004, 71:443-451.

47. Gray NS, Snowden RJ, MacCulloch S, Phillips H, Taylor J, MacCulloch MJ: Relative efficacy of criminological, clinical, and personality measures of future risk of offending in mentally disordered offenders: a comparative study of HCR-20, PCL:SV, and OGRS. I Consult Clin Psychol 2004, 72(3):523-30

48. Grevatt $M$, Thomas-Peter B, Hughes G: Violence mental disorder and risk assessment: can structured clinical judgement predict short term risk of inpatient violence. J Forens Psychiatry Psychol 2004, 15:278-92.

49. Quinsey V, Harris GT, Rice ME, Cormier C: Violence offenders: Appraising and managing risk Washington DC: American Psychological Association, 22006

50. Hare RD: The Hare Psychopathy Checklist-Revised Manual Toronto, Ontario: Multi-Health Systems 1991.

51. Hart SD, Cox D, Hare RD: The Hare Psychopathy Checklist: Screening version (PCL:SV) Toronto, Ontario: Multi-Health Systems 1995.

52. Hart SD: The role of psychopathy in assessing risk for violence: conceptual and methodological issues. Legal and Criminological Psychology 1998, 3:121-137.

53. Douglas KS, Ogloff J, Nicholls TL, Grant I: Assessing risk for violence among psychiatric patients comparison of the HCR-20 risk assessment scheme and the psychopathy checklist: Screening version. J Consult Clin Psychol 1999, 67:917-30.

54. Warren J, Burnette M, South S, Chauhan P, Bale R, Friend R: Psychopathy in women: Structural modelling and comorbidity. Int J Law Psychiatry 2003, 26:223-242. 
55. Vitale J, Newman JP: Using the Psychopathy Checklist Revised with female samples. Reliability, validity and implications for clinical utility. Clin Psychol 2001, 8:117-132.

56. Nicholls TL, Ogloff J: Assessing risk for violence among male and female civil psychiatric patients: The HCR-20, PCL, SV and the VSC. Behav Sci Law 2004, 22:127-158.

57. De Vogel V, Ruiter C: The HCR-20 in personality disordered female offenders: A comparsion with a matched sample of males. Clin Psychol Psychother 2005, 12:226-240.

58. Buchanan A: Risk of Violence by Psychiatric Patients: Beyond the "Actuarial Versus Clinical" Assessment Debate. Psychiatry Services 2008, 59:184-190.

59. Friendship C, McClintock T, Rutter S, Maden A: Re-offending: patients discharged from a regional secure unit. Crim Behav Ment Health 1999, 9:226-36.

60. Robertson G: Treatment for offender patients: how should success be measured? Med Sci Law 1989, 29:303-7.

61. James DV, Collings S: Prosecuting psychiatric inpatients for violent acts: a survey of Principles and Practice. The Royal College of Psychiatrists Annual Meeting 1989: Psychiatric Bulletin, Abstracts Supplement 1990, 2:60.

62. Smith J, Donovan M: The prosecution of psychiatric inpatients. J Forens Psychiatry Psychol 1990, 1:379-83.

63. Snowden P, McKenna J, Jasper A: Management of conditionally discharged patients and others who present similar risks in the community: integrated or parallel. J Forens Psychiatry Psychol 1999, 10:583-96.

64. Fujii DE, Tokioka AB, Lichton Al, Hishinuma E: Ethnic differences in prediction of violence risk with the HCR-20 among psychiatric inpatients. Psychiatr Serv 2005, 56(6):711-6.

\section{Pre-publication history}

The pre-publication history for this paper can be accessed here: http://www.biomedcentral.com/1471-244X/10/76/prepub

\section{doi:10.1186/1471-244X-10-76}

Cite this article as: Dolan and Blattner: The utility of the Historical Clinical Risk -20 Scale as a predictor of outcomes in decisions to transfer patients from high to lower levels of security-A UK perspective. BMC Psychiatry 2010 10:76.

\section{Submit your next manuscript to BioMed Central and take full advantage of:}

- Convenient online submission

- Thorough peer review

- No space constraints or color figure charges

- Immediate publication on acceptance

- Inclusion in PubMed, CAS, Scopus and Google Scholar

- Research which is freely available for redistribution 